\title{
Mobilidades de jovens de grupos populares do Rio de Janeiro em relação à rua e a casa
}

\author{
Mobilities of young people from popular groups of Rio de Janeiro \\ related to the streets and home
}

\section{Movilidades de jóvenes de grupos populares de Rio de Janeiro en relación con la calle y la casa}

\author{
Sabrina Dal Ongaro Savegnago 1 \\ '-UFRJ- \\ Brasil
}

Fecha correspondencia:

Recibido: febrero 14 de 2019.

Aceptado: octubre 30 de 2019.

Forma de citar:

Savegnago, S.D.O. (2020).

Mobilidades de jovens de grupos

populares do Rio de Janeiro em

relação à rua e a casa. Rev. CES Psico,

13(1), 52-69.

$\frac{\text { Open access }}{\text { C. Copyright }}$

Licencia creative commons

Etica de publicaciones

Revisión por pares

Gestión por Open Journal System

DOl: http://dx.doi.org/10.21615/

cesp.13.1.4

ISSN: 2011-3080

Sobre los autores:

1. Pós-doutoranda do Programa de Pós-Graduação em Psicologia. Doutora em Psicologia. Mestre em Psicologia. Graduada em Psicologia.

Comparte

A0G. $89 \mathbb{R}^{\circ}$ 圈

\section{Resumo}

Neste trabalho, tomamos como foco a experiência de jovens de grupos populares do Rio de Janeiro (Brasil) em relação à rua e a casa. Destacamos as várias facetas que estes espaços-tempos assumem para os jovens, tendo em vista o que nestes espaços limita e constrange suas mobilidades e o que se constitui como oportunidade para estes jovens. Foi realizado um estudo qualitativo, do qual participaram 51 jovens, habitantes de periferias urbanas e estudantes de $9^{\circ}$ ano do ensino fundamental, de duas escolas públicas municipais do Rio de Janeiro, com idades entre 14 a 16 anos. Foram realizados três grupos de discussão junto aos jovens, além de observações-participantes em ambas as escolas. Os dados foram analisados a partir da Análise de Conteúdo. Os resultados evidenciam que os jovens se deparam com inúmeros limites às mobilidades e situações inoportunas na rua, que compõem o que eles nomeiam como caos. Diante da imprevisibilidade negativa associada ao espaço da rua, o espaço doméstico é valorizado, principalmente por proporcionar a segurança que não pode ser encontrada na rua.

Palavras-chave: Jovens, Cidade, Grupos Populares, Juventude, Mobilidade, Oportunidade.

\section{Abstract}

This work is focused on the experiences lived by young people from popular groups in Rio de Janeiro (Brazil) related to the street and home. It is highlighted a variety of dimensions that these spaces and time offer to young people, taking into account the aspects that limit or constraints their mobilities in these spaces, and also what is considered and opportunity for them. It was performed a qualitative study, involving a total of 51 young people, being students in elementary schools, from two public municipal schools of Rio de Janeiro, aged between 14 and 16 and residents in urban peripheries. Three discussion groups were carried out with these students, in addition to participant-observations in both schools. The data were analyzed using the Analysis of Content. The results show that young people meet innumerable 
Pág 53

Integra o Núcleo de Pesquisa para Infância e Adolescência Contemporâneas (NIPIAC UFRJ). limits to their mobility and face untimely situations in the street, which constitute what they call chaos. Given the negative unpredictability associated with street space, domestic space is valued, mainly for providing security that cannot be found in the street.

Keywords: Youth, City, Mobility, Popular Groups, Opportunity.

\section{Resumen}

En este trabajo, nos centramos en la experiencia de jóvenes de grupos populares de Río de Janeiro (Brasil) en relación con la calle y la casa. Destacamos una variedad de facetas que estos espacios-tiempos asumen para los jóvenes, teniendo en cuenta lo que en estos espacios limita y constriñe sus movilidades y lo que se constituye como oportunidad para ellos. Se realizó un estudio cualitativo que involucró 51 jóvenes, habitantes de periferias urbanas y estudiantes de $9^{\circ}$ año de la enseñanza fundamental, de dos escuelas públicas municipales de Río de Janeiro, con edades entre 14 a 16 años. Se realizaron tres grupos de discusión con los jóvenes, además de observaciones-participantes en ambas escuelas. Los datos fueron analizados mediante el Análisis de Contenido. Los resultados evidencian que los jóvenes encuentran innumerables límites para su movilidad y enfrentan situaciones inoportunas en la calle, que constituyen lo que ellos nombran como caos. Ante la imprevisibilidad negativa asociada al espacio de la calle, el espacio doméstico es valorado, principalmente por proporcionar la seguridad que no se puede encontrar en la calle.

Palabras clave: Jóvenes, Juventud, Ciudad, Grupos Populares, Movilidades, Oportunidades.

\section{Introdução}

Nos últimos anos, com o foco crescente nas geografias de jovens, estudos vêm voltando sua atenção para as mobilidades dos jovens e a forma como estes utilizam o espaço na cidade (Chaves et al., 2017; Gough, 2008; Gough \& Franch, 2005; Segura, 2017; Skelton, 2013; Tapia, 2018; Winton, 2005). Neste trabalho, as noções de oportunidade e mobilidade foram tomadas como lentes a partir das quais foi analisada a relação dos jovens com os espaços da casa e da rua.

Consideramos oportunidade uma situação sentida pelo sujeito como favorável, que o move e o conduz para algum lugar, sendo percebida como tendo valor no aqui e no agora, mas podendo também repercutir de forma favorável no depois. A origem da palavra oportunidade ${ }^{1}$ remete à antiguidade romana, na qual Portunus era considerado o deus das chaves, das portas e, posteriormente, dos portos. Seu nome vinha de portus, relacionado com porta, o ponto de passagem para um aposento, para outro lugar. De ob-, significando "para, em direção a", e Portunus, se fez opportunus - o que empurra para o porto, ou seja, vento favorável, que move em direção a algo. 0 porto ou a porta impedem que se fique isolado, ilhado ou sem alternativa. Por isso, a oportunidade é aquilo que move, que tira do mesmo, pois o porto ou uma porta (aberta) possibilita movimento, entradas e saídas.

A mobilidade, como parte do processo de como nos engajamos com o mundo, se constitui em uma prática social de deslocamento através do tempo e do espaço, que possibilita o acesso a atividades, pessoas e lugares. Trata-se de uma ação que não se reduz à locomoção, ao movimento como trajeto que liga dois pontos, mas envolve,

1. Do livro "Qual é a tua obra?", de Mário Sérgio Cortella. Origem da palavra "oportuno". Disponível em: http://oriqemdapalavra.com.br/site/palavras oportuno/ Acesso em: 2 set. 2017 
Pág 54

Na cidade globalizada contemporânea, os encontros facilitados pela mobilidade podem aumentar a mobilidade social através da atribuição de capital social e cultural. Por outro lado, as mobilidades também podem oferecer indesejáveis encontros de confronto, medo ou perigo (Skelton, 2013). além das dimensões espaciais e temporais, aspectos corporais, simbólicos e afetivos, desigualmente vividos, em relação com a classe, o gênero, a idade, a etnia, o território, entre outras dimensões de desigualdade e diferença. A mobilidade dos sujeitos também possui uma dimensão relacional, uma vez que se torna compreensível na medida em que depende de (e/ou dela dependem) outras pessoas, atividades, meios e objetos (Chaves et al., 2017; Gough, 2008; Sheller, 2018; Skelton, 2013).

A mobilidade pode ser considerada uma marca distintiva dos tempos atuais e a vida social envolve com cada vez mais frequência o movimento de fato ou imaginário de pessoas de lugar a lugar, de evento a evento (Medeiros, 2016). Mover-se entre os locais pode fornecer oportunidades de encontros sociais que fazem parte dos complexos processos de tornar-se sujeito. Na cidade globalizada contemporânea, os encontros facilitados pela mobilidade podem aumentar a mobilidade social através da atribuição de capital social e cultural. Por outro lado, as mobilidades também podem oferecer indesejáveis encontros de confronto, medo ou perigo (Skelton, 2013).

Neste sentido, ressalta-se também a ideia do "capital de mobilidade", no que se refere à distribuição desigual das capacidades e condições, em relação aos recursos físicos, sociais e políticos circundantes para o movimento, considerando também as estruturas legais que regulam quem ou o que pode e não pode se mover. Portanto, a mobilidade e seu contraponto - a imobilidade (fixidez) - relacionam-se com geografias e políticas de poder (Skelton, 2013).

De acordo com Cresswell (2010), a mobilidade se constitui em um "movimento socialmente produzido", uma atividade geográfica humana imbuída com significado e poder. Neste sentido, se a possibilidade de deslocar-se entre locais pode ser uma fonte de status e poder, nem todos têm uma relação de igualdade com a mobilidade (Langevang \& Gough, 2009). Desse modo, é importante salientar que o status socioeconômico influencia diretamente nas políticas de acesso à mobilidade (Skelton, 2013) e na possibilidade de dominação e ocupação dos espaços. A posse do capital permite aproximar o que é desejável e afastar ou manter distantes indivíduos e objetos a ele indesejáveis. A proximidade no espaço físico e social dos bens desejáveis possibilita maior acesso e propicia a reprodução do domínio econômico e simbólico dos meios de circulação e comunicação na cidade (Cassab, M. A. T., Ribeiro \& Schettino, 2005).

Ao atentarmos para os processos de urbanização na sociedade brasileira, observa-se uma ocupação bastante desordenada e desigual do espaço urbano, que resultou em profundas segregações. Estas implicam que os sujeitos tenham acessos desiguais à estrutura objetiva de oportunidades e aos equipamentos sociais disponíveis no espaço urbano. Os centros culturais, as áreas de lazer e os principais centros acadêmicos geralmente estão concentrados nas zonas mais ricas da cidade, distantes da periferia (Cassab, M. A. T. \& Reis, 2009). Os jovens que habitam regiões com carência de infraestrutura tendem a ficar mais limitados ao seu bairro de origem e, consequentemente, restritos às precárias, e por vezes inexistentes, possibilidades culturais e espaços de lazer (Borelli \& Rocha, 2008; Cassab, C. \& Mendes, 2011; Duarte, 2014). Desse modo, enquanto uma minoria pode usufruir plenamente dos benefícios oferecidos pela cidade, uma grande parcela da população encontra-se excluída do direito à cidade e ao que ela poderia oferecer e oportunizar. Neste sentido, a possibilidade de acesso ao que a cidade tem a oferecer, a classe social a que pertence o sujeito e seu local de moradia são aspectos interconectados, uma vez que a questão do poder e da posse do capital estão diretamente associados à possibilidade de mobilidade e à ocupação de determinados espaços. 
Realizou-se uma pesquisa de cunho qualitativo, na qual participaram 51 jovens (25 meninas, 26 rapazes), com idades entre 14 a 16 anos, estudantes de $9^{\circ}$ ano do ensino fundamental, de duas escolas públicas municipais (Escola 1 e Escola 2) do Rio de Janeiro. A maioria dos jovens residia em favelas da Zona Central da cidade e pertencia a famílias de baixa renda.
Neste trabalho, tomamos como foco a experiência de jovens de classes populares, habitantes de periferias urbanas do Rio de Janeiro, em relação à rua e a casa. Buscamos compreender os vários significados que a rua e a casa assumem para os jovens e o que nestes espaços-tempos se constitui enquanto oportunidade, bem como o que limita e constrange suas mobilidades.

\section{Método}

Realizou-se uma pesquisa de cunho qualitativo, na qual participaram 51 jovens (25 meninas, 26 rapazes), com idades entre 14 a 16 anos, estudantes de $9^{\circ}$ ano do ensino fundamental, de duas escolas públicas municipais (Escola 1 e Escola 2) do Rio de Janeiro. A maioria dos jovens residia em favelas da Zona Central da cidade e pertencia a famílias de baixa renda.

Foram realizados três grupos de discussão (Grupo 1 - G1 e Grupo 2 - G2, realizados na Escola 1 e Grupo 3 - G3, na Escola 2), que ocorreram no formato de oficinas. As oficinas tiveram um número médio de 12 participantes por encontro, tendo no mínimo oito e no máximo 16 jovens. Foram realizadas sete oficinas com o grupo 1 , oito oficinas com o grupo 2 e 10 oficinas com o grupo 3, totalizando 25 encontros. Os encontros tiveram duração média de $1 \mathrm{~h}$ e 22 min, com duração mínima de 50 minutos e máxima de 2 horas.

As oficinas foram divididas em cinco módulos (1 - De casa para a escola; 2 - Da escola pra casa; 3 - De casa para outros lugares; 4 - Lugares bem longe de casa; 5 - Conversando sobre oportunidade), nos quais foram propostas algumas atividades, como a criação de desenhos, maquetes e histórias, que foram utilizados como recursos auxiliares para motivação, imaginação e discussão. Apenas os módulos 1 e 2 serão aqui detalhados, por estarem mais relacionados às questões discutidas neste artigo.

A atividade "De casa para a escola" consistiu na criação, em grupos de 3 a 5 pessoas, de um desenho-história que mostrasse como seria o trajeto de casa para a escola de um(a) jovem como eles. As seguintes perguntas, destacadas em um cartaz, foram utilizadas como guia para a criação da história: Como esse(a) jovem vai à escola? 0 que acontece nesse trajeto? 0 que ele(a) faz? Quem encontra? Com quem fala? 0 que vê? Como se sente? Do que mais gosta? Algo especial acontece? 0 que ele(a) gostaria que acontecesse nesse trajeto? Além disso, foi proposto que os(as) jovens incluíssem na história elementos sobre a chegada dessa personagem na escola e descrevessem situações que costumam acontecer na escola. Na atividade "Da escola pra casa", os participantes foram convidados a contar, através de um desenho individual, a história de um(a) jovem como eles que realiza o trajeto da escola para casa. As mesmas questões-guia apresentadas na atividade "De casa para escola" foram utilizadas para balizar a história do percurso escola-casa.

A proposta de realização das oficinas foi recebida de forma diferente pelos jovens das duas escolas. A maioria dos participantes da escola 2 (G3) referiram os encontros como um espaço de escuta importante, que deveria ter uma continuidade. Segundo estes jovens, o espaço propiciou que pudessem falar sobre as barreiras encontradas em seus deslocamentos pela cidade, sobre as angústias e incertezas em relação ao amanhã, sobre as desigualdades de acesso às oportunidades, dentre outras questões. Já na escola 1 (G1 e G2), a participação dos alunos precisou ser constantemente negociada com eles, uma vez que, em alguns momentos, estes jovens manifestavam desinteresse por algumas atividades propostas. Observou-se a tentativa de alguns jovens de evitar as atividades propostas nas oficinas que se assemelhavam às tarefas escolares, que 
Pág 56

A partir do campo empírico, foi possível observar que, em suas mobilidades, principalmente no caminho de casa para a escola e da escola para casa, os jovens são confrontados com o pior da cidade - o egoísmo, o desrespeito, a falta de amor e solidariedade, a miséria, a agressividade, a violência e a insegurança, elementos que compõe o que os participantes do G3 nomearam como "caos". pareciam ser sentidas como tediosas e sem sentido, através da sugestão de atividades que tinham mais relação com seus interesses naquele momento, como jogar futebol ou outros jogos, realizar as oficinas em espaços fora da escola, ou mesmo fora da sala de aula, no que parecia ser uma busca pela negociação de formas de tornar aquele um espaço para fruição e diversão. Neste sentido, os jovens participantes desenvolveram um papel ativo durante o curso do processo de pesquisa, inclusive no que se refere à re(elaboração) de alguns recursos e procedimentos que seriam utilizados nas oficinas. Destaca-se assim que estar no campo e deixar-se afetar por ele implica em estar disposto a acolher o imprevisível no curso do processo e, quando necessário, ressignificar a proposta de pesquisa a partir das demandas que vêm dos participantes.

Os encontros foram gravados e transcritos, e foi realizado o registro fotográfico dos desenhos produzidos durante as oficinas, para posterior Análise de Conteúdo (Bardin, 1977/2011). Além das oficinas, foram realizadas observações participantes em ambas as escolas, as quais foram registradas em diários de campo. Buscando manter o anonimato dos jovens, seus nomes foram substituídos por nomes fictícios ao longo do texto.

Neste trabalho, foram respeitadas as diretrizes éticas para pesquisas com seres humanos propostas pela Resolução do Conselho Nacional de Saúde (CNS) n 510/2016, normativa nacional brasileira que estabelece uma regulamentação específica para pesquisas em Ciências Humanas e Sociais. Este estudo foi submetido e aprovado em seus aspectos éticos e metodológicos pelo Comitê de Ética em Pesquisa do Centro de Filosofia e Ciências Humanas da Universidade Federal do Rio de Janeiro, sob o parecer $n^{\circ} 1.518 .016$ e Certificado de Apresentação para Apreciação Ética (CAAE) nº 54208116.9 .0000 .5582 .

Algumas discussões em torno da questão das mobilidades em relação à casa e a rua tomaram certa força nas narrativas dos jovens e, a partir das análises, foram organizadas em torno das seguintes categorias: (1) o que a rua oferece de (in)oportuno aos jovens; e (2) a segurança da experiência doméstica em contraposição ao caos da rua, as quais serão apresentadas e discutidas na seção a seguir.

\section{Resultados e discussão}

\section{0 que a rua oferece de (in)oportuno aos jovens}

A partir do campo empírico, foi possível observar que, em suas mobilidades, principalmente no caminho de casa para a escola e da escola para casa, os jovens são confrontados com o pior da cidade - o egoísmo, o desrespeito, a falta de amor e solidariedade, a miséria, a agressividade, a violência e a insegurança, elementos que compõe o que os participantes do G3 nomearam como "caos". No encontro com o caos da experiência urbana, os jovens se deparam com poucas garantias e muitas imprevisibilidades e a fortuidade que caracteriza tais mobilidades aparece quase sempre com um caráter negativo e inoportuno.

Pesquisadora: E o que ela [personagem] vê nesse caminho?

Fabiana: Muito caos.

Clara: Ela vê muita gente descendo a ladeira pra ir pra escola... Muita fumaça dos carros na cara dela...

Jaqueline: Vejo muito bandido...

Clara: Armado...

Jaqueline: É. Muitos policiais também... (G3, $2^{\circ}$ encontro) 
Os jovens também referiram que, nestes deslocamentos pela cidade, sempre existe a possibilidade de algo acontecer repentinamente (tiroteios, roubos, atropelamentos), o que provoca uma sensação de insegurança, ou até mesmo a restrição de suas mobilidades.

Pesquisadora: E alguma coisa acontece nesse caminho de diferente, de especial? Clara: Só quando tem Bope ${ }^{2}$ no morro.

Jaqueline: Se eles encontrar os garotos vai dar tiro, aí a gente tá no meio de tiro...

Clara: $E$ às vezes não dá pra vir pra escola quando dá tiro lá em cima. (G3, $3^{\circ}$ encontro)

Os conflitos e a violência associados ao tráfico resultam, muitas vezes, na limitação da mobilidade dos jovens moradores das favelas e em seu confinamento em suas próprias casas, o que é referido pelos participantes quando, por exemplo, afirmam que várias vezes já deixaram de ir para escola por causa de confrontos entre facções do tráfico, ou entre traficantes e a polícia.

Nesta cidade em que o caos e a fortuidade negativa marcam as mobilidades destes jovens, o imprevisível e o incontrolável do convívio entre os diferentes são suscetíveis de serem vividos e experimentados. Em relação a este aspecto, os jovens destacaram a vivência de tensões e dificuldades no encontro com o outro na cidade.

Os jovens do G3, por exemplo, relataram desde o primeiro encontro seu incômodo diante da hostilidade nas relações entre os sujeitos, presenciadas durante seus deslocamentos pela cidade. 0 egoísmo, o desrespeito e o distanciamento afetivo foram os elementos mais destacados.

Raiane: Eu quero representar a falta de amor que eu vejo no dia a dia... (G3, $1^{\circ}$ encontro). Aí você vê as pessoas mal educadas, desonestas com o próximo. E não têm amor próprio... Elas só estão pensando nelas mesmas (Figura 1) (G3, $2^{\circ}$ encontro).

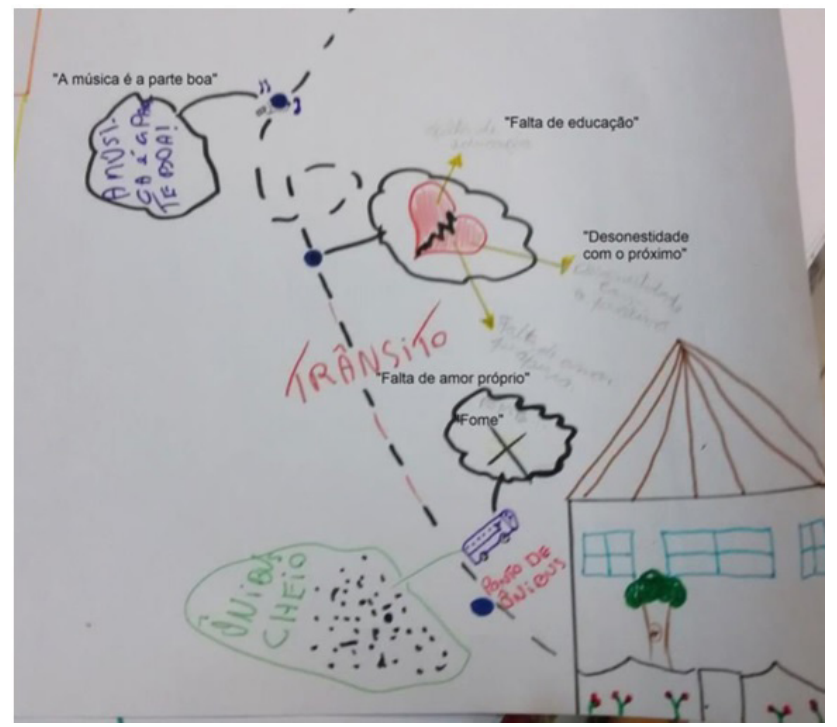

Figura 1. De casa para a escola (Raiane, G3). 
Pág 58

Ao esbarrar ou se aproximar deste outro/diferente/ estranho em suas mobilidades, este encontro muitas vezes pode ser inoportuno, uma vez que os jovens experimentam diversos constrangimentos e sentem na pele os preconceitos e a imposição de barreiras reais e simbólicas às suas mobilidades no espaço urbano.
Estes aspectos que permeiam as relações interpessoais na cidade, sinalizados pelos jovens, relacionam-se com algumas ideias de Kuster e Pechman (2014a), que assinalam que nos últimos anos vem ocorrendo em nossas cidades uma diminuição da solidariedade e, consequentemente, um aumento da intolerância. Vem sendo trilhado um percurso inverso ao realizado até então, "que havia sido composto por acordos estabelecidos entre todos que dividiam e necessitavam compartilhar o espaço urbano" (p. 12). Tais acordos conferiam um mínimo de garantia à existência da cidade, com suas diversidades. No entanto, à medida que o papel destes acordos retrai, obscurecido pela insegurança, pelo medo, pelo individualismo e pela violência, o espaço urbano vem sendo cada vez mais marcado pela intolerância e pelo resguardo individual.

Ao esbarrar ou se aproximar deste outro/diferente/estranho em suas mobilidades, este encontro muitas vezes pode ser inoportuno, uma vez que os jovens experimentam diversos constrangimentos e sentem na pele os preconceitos e a imposição de barreiras reais e simbólicas às suas mobilidades no espaço urbano. Neste sentido, o local de moradia, a raça, o gênero, a classe social, o estilo, a aparência, a forma de vestir e o fato de ser aluno de escola pública - o que é identificado pelo uso do uniforme escolar - foram apontados pelos jovens como fatores que se tornam fonte de estigmas e preconceitos e, desse modo, além de constrangê-los subjetivamente, podem contribuir para a restrição real de suas mobilidades.

O julgamento do outro a partir da aparência foi uma questão salientada por Wagner, que faz algumas observações em relação aos (des)encontros que ocorrem em suas mobilidades pelas ruas da cidade.

Wagner: Tem gente que me vê assim e pensa várias coisas ruins, mas porque não me conhece. É que nem eu digo: tu nunca pode julgar o livro pela capa. Pesquisadora: Mas o que tu acha que as pessoas pensam de ti?

Wagner: Não me conhece aí pensa que eu...

Jaqueline: Mais por causa da cor dele... Acham que todos da cor dele fazem tipo... que rouba, que faz coisa errada...

Wagner: Eu posso gravar se tu quiser. Eu ando na rua assim, sozinho. 0 meu estilo é esse. Se eu vou sair pra comprar alguma coisa, eu não vou sair todo produzido. Tipo, eu vou botar uma bermuda, um chinelo, uma camiseta... tô indo. (...) Aí se tiver passando alguém, no caso, mulher ou senhoras... Jaqueline: Já segura a bolsa.

Wagner: Quando me vê já tá com a bolsa aqui debaixo do braço. Que nem ontem ó, eu juro, eu tinha acabado de guardar o meu cavalo, aí eu estava vindo embora, e estava vindo um rapaz e uma mulher... Eu estava lá embaixo, lá no túnel, aí estava vindo a mulher e o cara, eles olharam pra trás, me olharam com uma cara que me deu vontade de rir. Mano, só faltou eles saírem correndo. Eles aceleraram o passo, a mulher tinha a bolsa aqui do lado e começou a andar rápido. Aí eu passei no lado dela e ela ficou olhando assim [expressão desconfiada]. Aí eu disse boa noite, passei, aí ela deu aquela respirada aliviada. (G3, $8^{\circ}$ encontro)

Em relação a esse aspecto, consideramos a afirmação de Maria Aparecida Cassab (2001), de que a cidade "como 'outro', espelho que 'dialoga' com o sujeito na produção de si mesmo", possibilita identificações e permite ao sujeito reconhecer-se a partir da imagem que lhe é devolvida. No entanto, para os jovens que trazem em si marcas visíveis de sua desvantagem social, a cidade é um "espelho de alta reflexão" (p. 211). No caso de Wagner, o olhar do outro e seu comportamento diante de sua 
A polícia, a partir do que se pode ver a nível da superfície dos corpos dos jovens, produz uma marcação seletiva, que determina quem será retido no espaço público e quem poderá circular sem inconvenientes (Bonvillani, 2017). presença lhe devolvem uma imagem de si que ele sente como não sendo sua. 0 outro lhe transmite a ideia de que ele não deveria estar circulando por aquele espaço, que não é bem vindo ali, por ser identificado, a partir da cor de sua pele e forma de se vestir, como alguém que pode representar uma ameaça e que possui menos valor. Trata-se de uma "visibilização negativa" (Segura, 2017), que conjuga estigmas territoriais com estigmas ligados à aparência, em que se entrelaçam dimensões etárias, estéticas, corporais, dentre outras. Neste sentido, o "direito ao anonimato" - que permite às pessoas moverem-se pelo espaço público sem dar explicações - é negado aos jovens de classes populares (Segura, 2017).

A questão da revista policial, realizada de forma arbitrária e desrespeitosa, baseada em determinados estereótipos, também foi muito recorrente nas discussões durante as oficinas.

André: É... muito constrangedor! Várias vezes isso... É pela área que a gente mora. Várias vezes, é constrangedor. Tipo assim, no meio da rua, várias pessoas pa- ssando e tu sendo revistado. É uma coisa muito ruim... (G3, $1^{\circ}$ encontro)

Quase metade dos jovens participantes do G3 já havia passado ao menos uma vez por uma situação de revista policial. É importante ressaltar que todos eles eram moradores de favelas, e que, por outro lado, todos os jovens deste grupo que não relataram terem sido revistados por policiais não residiam em favelas. Além da questão do local de moradia, os jovens relacionaram este tipo de ação policial com o preconceito relacionado à cor da pele, ao estilo e à forma de se vestir de certos jovens.

Giovana: Se for um pouquinho diferente...

Pesquisadora: Diferente como?

Giovana: 0 André, por exemplo, que você conheceu. Ele tem um estilo todo largado, ele anda de chinelo, bermuda, boné... ele é muito largado. Aí ele já me contou que uma vez um policial abordou ele só por causa da roupa dele, porque pensou que ele era bandido. Aí ele mostrou a identidade, ele sempre anda identificado, ele mostrou a identidade dele e o cara viu que ele não tinha nada. Só que abordaram ele só pelo jeito dele. (...)

Jaqueline: "Ele tem cara de bandido...".

Clara: Ou pela cor dele... (G3, $3^{\circ}$ encontro)

Estes relatos são ilustrativos de uma realidade em que os jovens pobres, negros e residentes em comunidades periféricas são cada vez mais identificados a partir de estereótipos que os enquadram como potencialmente perigosos, tornando-se objeto de maior vigilância, atraindo os olhares carregados de preconceitos: da sociedade que deposita nesses jovens a responsabilidade pelo aumento da criminalidade e do aparato policial que os identifica como "suspeitos" (Bonvillani, 2017; Cassab, C., 2010b; Cassab, M. A. T., 2001b; Castro, 2004; Coimbra \& Nascimento, 2003; Gough \& Franch, 2005; Pérez; \& Castro, 2011). Assim, a polícia, a partir do que se pode ver a nível da superfície dos corpos dos jovens, produz uma marcação seletiva, que determina quem será retido no espaço público e quem poderá circular sem inconvenientes (Bonvillani, 2017). Em relação a este aspecto, destacamos as contribuições de Cecchetto, Muniz e Monteiro (2018) que, a partir de uma pesquisa etnográfica realizada junto a jovens de duas favelas cariocas, referem e problematizam a categoria "envolvido-com" o crime e suas serventias. Trata-se de um dispositivo itinerante de incriminação, de controle social e uma noção que tem sido mobilizada na distribuição seletiva de suspeição e vigilância e de punição das juventudes da periferia. 
Pág 60

O temor em relação à violência de gênero é um dos fatores que mais influencia na restrição da mobilidade urbana das mulheres, limitando suas opções de deslocamento, o uso de determinados serviços e a ocupação de determinados espaços.
Neste estudo foi possível observar, a partir dos relatos dos jovens, a produção de diversos constrangimentos a partir dos espaços, onde barreiras reais e simbólicas se impõem àqueles que não são bem-vindos e são produzidas estratégias de afastamento dos "indesejáveis", dentre os quais se situam principalmente os jovens pobres e negros, e de isolamento e contenção de territórios considerados perigosos. Ou seja, nega-se a estes sujeitos o direito ao pleno acesso e ao uso da cidade (Dimenstein, Zamora, \& Vilhena, 2004; Lannes-Fernandes, 2014; Saraví, 2014; Segura, 2017; Tapia, 2018).

Outro aspecto apontado pelas jovens do G3, que constrange suas mobilidades e faz parte do caos com o qual se deparam na cidade, é o assédio masculino. As cantadas, os olhares libidinosos, o desrespeito e a possibilidade de agressão sexual são sentidos como ameaçadores, como algo que viola seu direto de deslocar-se livremente. As jovens relatam nunca sentirem-se totalmente tranquilas para mover-se por estes espaços, referindo uma vigilância constante. Desse modo, o assédio coloca as mutheres em uma posição de inferioridade e a rua acaba sendo marcada como um lugar que pertence aos homens e onde elas não têm liberdade para mover-se com tranquilidade por onde, quando e como gostariam.

Ao pensar as relações de gênero na cidade, podemos considerar a tradicional dicotomia que contrapõe casa e rua, em relação à qual se estabelecem as séries opostas casa-privado-feminino e rua-público-masculino. Apesar dos sentidos sedimentados nos discursos sociais, a experiência cotidiana das mulheres não se circunscreve necessariamente ao âmbito da casa, nem a dos rapazes ao âmbito da rua. As mobilidades cotidianas dos(as) jovens revelam um cenário mais complexo, que desestabiliza e vai além dessa dicotomia casa e rua relacionada ao gênero (Chaves et al., 2017). Mesmo assim, podemos afirmar que as jovens se movem pela cidade sendo mais constrangidas em seus deslocamentos e mais vigiadas e controladas pelos adultos, quando comparadas aos rapazes. 0 temor em relação à violência de gênero é um dos fatores que mais influencia na restrição da mobilidade urbana das mulheres, limitando suas opções de deslocamento, o uso de determinados serviços e a ocupação de determinados espaços.

Considerando as diversas discriminações e restrições ao deslocamento vivenciadas por estes jovens em suas mobilidades na rua, nos questionamos se eles ainda conseguem vislumbrar oportunidades em suas experiências e mobilidades no espaço urbano. 0 aspecto oportuno que mais se destacou entre os jovens participantes foi a possibilidade de desfrute, entretenimento e convívio com os pares que a mobilidade pela rua lhes oferece. Nestes percursos, é possível encontrar os pares para conversar, namorar, zoar, lanchar, ou até para "fazer nada". Não parece ser conferido um sentido negativo a esse tempo de "fazer nada", que parece ser acompanhado de prazer e fruição.

Mariana: Eu gosto de ficar em casa, na rua...

Laís: Vagabundear é a melhor coisa...

Pesquisadora: Ah é? Onde que é bom vagabundear?

Laís e Roberta: Na rua.

Mariana: Na escada dela [amiga]... Onde sobe pra casa dela tem uma escada. A gente gosta de ficar lá. (G1, $1^{\circ}$ encontro) 
Chama atenção que, mesmo diante de tantos constrangimentos, os jovens continuam indo para a rua. Mesmo afirmando sentirem-se mais seguros em casa, eles não deixam de se deslocar pela cidade, de buscar oportunidades e oportunizar para si através de suas mobilidades neste espaço. Para isso, eles lançam mão de algumas formas de agenciamento desses muros e constrangimentos, através de linhas de fuga ou escapes.
Outro aspecto evidenciado nas oficinas foi que o trajeto dos jovens de casa para a escola ou da escola para casa não se realiza sempre de forma retilínea, mas podem ocorrer perambulações que desviam do caminho comumente realizado, por conta de distrações com os amigos, ou ainda devido à ocorrência de algo inesperado, como afirma Luana: "Às vezes eu encontro alguns amigos, às vezes eu vou pra um lugar diferente. Não daqui pra casa e sim pra outros lugares" (G3, $4^{\circ}$ encontro).

A rua como um lugar de encontro com o outro, que em algumas situações pode oportunizar o contato com novas experiências, também foi um aspecto mencionado pelos jovens. Este outro pode ser um amigo que fala sobre a possibilidade de entrar em contato com algo que interessa ao jovem, ou que o leva junto para experienciar algo diferente, que posteriormente pode ser sentido e reconhecido como uma oportunidade. Este outro também pode ser alguém que aposta no jovem, que vê nele um potencial e investe nisso. Ou seja, a mobilidade pela rua pode levar ao contato com alguma oportunidade que remeta o jovem para algo e algum outro lugar, além do presente imediato, que é sentido como favorável.

Chama atenção que, mesmo diante de tantos constrangimentos, os jovens continuam indo para a rua. Mesmo afirmando sentirem-se mais seguros em casa, eles não deixam de se deslocar pela cidade, de buscar oportunidades e oportunizar para si através de suas mobilidades neste espaço. Para isso, eles lançam mão de algumas formas de agenciamento desses muros e constrangimentos, através de linhas de fuga ou escapes. Por exemplo, mover-se mais rápido e com cautela, evitar determinados lugares, andar na rua na companhia de alguém (sobretudo no caso das meninas), ou até utilizar fones de ouvido para escutar músicas enquanto se movem pela cidade, como uma busca por momentos de introspecção e distanciamento da percepção do caos urbano.

A partir do exposto até o momento, foi possível observar que, para estes jovens, a mobilidade no espaço público parece possibilitar boas experiências, bons encontros e oportunidades, mas também, e principalmente, pode envolver constrangimentos, limitações às mobilidades e insegurança. Neste sentido, frente a esta experiência de imprevisibilidade negativa que muitas vezes é associada ao espaço da rua, que pode ser sentido pelos jovens como hostil e inoportuno, outro espaço acaba sendo visto como um refúgio e revestido de importância e valor: a casa.

\section{A segurança da experiência doméstica em contraposição ao caos da rua}

A casa foi referida por vários jovens como um lugar bom para se estar, onde se pode desfrutar de algumas atividades que envolvem descanso, lazer e distração, como assistir filmes e séries, utilizar o celular, navegar na internet, jogar vídeo game, escutar música e dormir. Heitor, por exemplo, diz que no fim de semana permanece a maior parte do tempo em casa, onde ele gosta de estar, pois "lá tem tudo o que ele precisa: sinal de wifi, cama, comida e água" (G3, 5ºncontro). Além de Heitor, vários outros jovens destacaram a atração exercida pelo espaço da casa.

Guilherme: Quando eu chego em casa, é fogos de artifício, é maravilha! Dá mortal duplo carpado, pulo na cama. Aí ligo o computador... é magia, felicidade, amém! (Figura 2) (G3, $4^{\circ}$ encontro). 


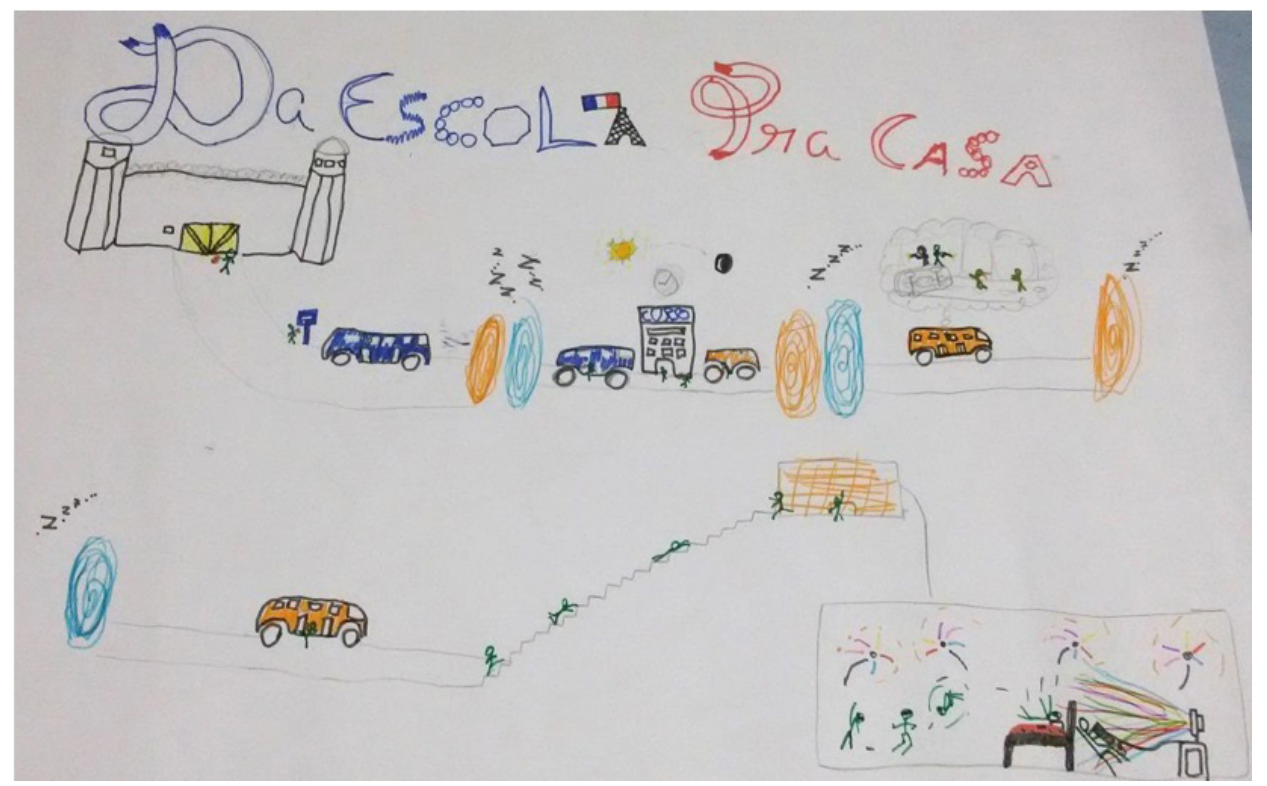

Figura 2. "Quando chego em casa é maravilha" (Guilherme, G3).

Também foi possível observar diferenças de gênero em relação às atividades realizadas em casa (Nascimento, 2013; Senkevics \& Carvalho, 2015). Enquanto os meninos raramente se referiram à ocupação com tarefas domésticas, para muitas das jovens chegar em casa significa assumir a responsabilidade pelo cuidado dos irmãos e pelas tarefas domésticas, principalmente nos casos em que suas mães ou responsáveis trabalham fora de casa.

Luana: Aí eu chego em casa, aí a casa tá uma zona... Aí eu tenho que arrumar a casa, que as minhas irmãs são muito bagunceiras. Quando a gente sai de manhã, a gente deixa tudo bagunçado. Depois disso, por exemplo, hoje eu vou levar a minha irmã no ballet, depois vou voltar pra minha casa, vou mexer no celular. Ai, é muito viciante!! [Risos]. Quando der 19:30, 19:45, eu busco elas no ballet... Depois vou ficar lá em casa gritando com elas porque elas são muito bagunceiras. Aí, só! Espero minha mãe chegar. Aí tem dias que ela faz a comida, quando ela não tá muito cansada, aí tem dias que eu faço. (G3, $1^{\circ}$ encontro). Pesquisadora: E o que ele [personagem] faz em casa?

Adriana: Se for um menino, nada. Se for uma menina, arruma a casa. (G2, $3^{\circ}$ encontro)

Além de ser um lugar onde grande parte dos jovens referiu poder realizar atividades que gostam e que os distraem, relacionadas ao desfrute do agora, em termos de projetos a casa foi apontada por um pequeno número de jovens como um espaço onde é possível dedicar-se aos estudos e à preparação para algo relacionado a um depois. No fim de semana, por exemplo, Raiane (G3) se divide entre aproveitar o momento do agora, divertindo-se e descansando, e estudar para concursos.

Como afirma Castro (2004), o estudo no espaço da casa pode remeter à antecipação do que ele pode significar para o jovem, além do momento silencioso e solitário. Ele se realiza na permanência da casa, em um presente que ancora o futuro, ou seja, no presente que pode ser tanto movimento em relação ao depois e a outros lugares, quanto permanência no hoje, no sentido de preparar o sujeito para o movimento. 
Para os jovens do presente estudo, em casa é possível experienciar entretenimento e fruição, além de mobilidades virtuais, principalmente através do acesso à Internet, pelo celular e/ou computador. Apesar de a casa estar pouco povoada durante o dia, isto não foi referido como algo negativo pelos jovens, uma vez que a Internet pode possibilitar o contato virtual com os pares.
Ele implica em uma "construção de si introspectiva, silenciosa e dirigida a um outro lugar que não a casa, mas àquilo que pode ser obtido com o estudo - "um lugar ao sol" na cidade competitiva, um trabalho no tempo ulterior" (Castro, 2004).

Desse modo, para alguns jovens, a casa se constitui em um espaço onde é possível "ficar mais introspectivo" (G3, 5 encontro), como afirma Raiane, pensar na vida e no que se deseja, planejar algo, mesmo que seja a curto prazo, ou seja, um espaço onde é possível encontrar-se consigo mesmo. Nestes casos, podemos verificar exemplos de como a imobilidade também pode oportunizar. Ou seja, mesmo na permanência na casa, para alguns jovens é possível deslocar-se subjetivamente e imaginariamente para outros lugares.

Assim, seja como espaço onde é possível aproveitar o aqui e o agora ou planejar o amanhã, foi possível constatar que, para os jovens, a casa parece ser um lugar diferente do espaço da rua. Em relação a este aspecto, destacamos o estudo "Aventura urbana", realizado por Castro (2004), com crianças e jovens do Rio de Janeiro, que mostra uma experiência doméstica diferente da vivenciada pelos jovens do presente estudo. Para os participantes do estudo de Castro, o espaço da casa não é associado ao entretenimento, ao prazer e à mobilidade, é um lugar com poucas opções de coisas para fazer, além das tarefas e obrigações, e que costuma estar despovoado de pessoas durante o dia, o que torna a experiência doméstica solitária em grande parte do tempo.

Por outro lado, para os jovens do presente estudo, em casa é possível experienciar entretenimento e fruição, além de mobilidades virtuais, principalmente através do acesso à Internet, pelo celular e/ou computador. Apesar de a casa estar pouco povoada durante o dia, isto não foi referido como algo negativo pelos jovens, uma vez que a Internet pode possibilitar o contato virtual com os pares. Mesmo considerando que a pesquisa aqui retratada envolveu apenas duas escolas, enquanto o estudo de Castro (2004) teve uma abrangência muito maior, chama atenção a diferença em relação a alguns aspectos que os resultados destas duas pesquisas trazem, sinalizando para algumas mudanças importantes que parecem ter ocorrido nos últimos anos. Em relação a estas transformações, podemos considerar que, em 2004, ano da publicação da pesquisa de Castro, a internet não ocupava um papel tão importante na vida de muitos jovens e que, nos últimos anos, houve um aumento significativo da violência no espaço urbano. Isto nos mostra que estamos vivenciando profundas transformações nas relações sociais, que alteram significativamente as formas como nos produzimos enquanto sujeitos.

Quando questionados sobre o que havia de bom e atrativo em casa, a maioria dos jovens mencionou a possibilidade de acesso à internet através do computador e/ou dos celulares. Desse modo, eles parecem valorar positivamente a casa principalmente pela mobilidade virtual que pode ser realizada na permanência neste espaço, bem como pela segurança que não pode ser encontrada na rua.

As mobilidades virtuais, realizadas principalmente no espaço doméstico, ocupam um lugar significativo na vida de muitos destes jovens. Diante da crescente necessidade de proteger-se do outro, o advento das novas tecnologias surge como uma possibilidade de interação com os demais que dispensa os aspectos físicos do encontro interpessoal e mantém o sujeito dentro de certa "bolha de segurança". Assim, "a aventura agora estaria na Internet e não mais na cidade" (Kuster \& Pechman, 2014b, p. 194). 
Pág 64

Estar seguro equivale a estar em casa, nutrido e sem riscos, longe dos perigos da rua. Assim, "sair de casa" - de forma literal e metafórica -, pode significar o abandono de um estado de segurança para se entrar em contato com as tensões da vida em comum (Castro, 2013).
No passado, a casa era sentida muitas vezes como um lugar pouco atraente ao jovem, por ser associada ao tédio, à monotonia e ao "sempre igual", enquanto a rua, apesar do receio da novidade, exercia maior atração e fascínio por oferecer possibilidades de trocas e descobertas. Hoje, estas possibilidades podem ser acessadas através da Internet, que muitas vezes está disponível para os jovens no espaço da casa. Além disso, observa-se que a antiga atração exercida pela rua parece ter dado lugar ao receio de encontrar-se com o outro e à sensação que acompanha cotidianamente qualquer morador de uma cidade grande: a necessidade de proteção (Kuster \& Pechman, 2014b).

Winton (2005), ao analisar o impacto da atividade de gangues juvenis em jovens membros e não-membros na Cidade da Guatemala, observou que, no geral, os jovens não diretamente envolvidos com gangues pareciam gastar muito pouco tempo fora da escola ou da casa (mesmo no fim de semana), seja com amigos ou praticando esportes. A maioria passava o tempo livre em casa, com a família, em atividades solitárias, como a leitura, o desenho ou assistindo TV. 0 motivo desse distanciamento da vida pública foi o perigo incontrolável associado à violência em geral e às gangues em termos de assaltos e combates territoriais. Assim, a violência tem efeitos na restrição ao desenvolvimento e à manutenção de redes sociais juvenis e à participação em atividades sociais fora de casa (Winton, 2005).

Em relação à questão da segurança, para alguns jovens, a chegada em casa vem acompanhada de uma sensação de alívio e proteção, após a vivência de situações tensas em seus trajetos pela cidade.

Pesquisadora: E como você se sente quando chega em casa?

Giovana: Aliviada. É bom chegar em casa sabendo que eu não fui assaltada ou estuprada... (...). É o que eu mais tenho medo quando chego no meu bairro. (...) Eu sempre fico aliviada quando a gente chega em casa e a gente chegou bem, tanto eu quanto meu irmão.

Brenda: Eu também vejo muita poluição de carros, motos, caminhões, ônibus... isso faz mal pra mim. Aí eu vou pra casa, trato a minha bronquite... e eu me sinto aliviada porque eu tô em casa, tô segura...

Heitor: Em paz... (G3, $4^{\circ}$ encontro)

Neste caso, estar seguro equivale a estar em casa, nutrido e sem riscos, longe dos perigos da rua. Assim, "sair de casa" - de forma literal e metafórica -, pode significar o abandono de um estado de segurança para se entrar em contato com as tensões da vida em comum (Castro, 2013).

Em uma das oficinas do grupo 2, alguns jovens criaram um desenho-história (Figura 3) emblemático, que diz muito desta contraposição entre a casa e a rua apresentada pelos participantes e sobre a problemática do convívio com o outro. A história foi construída de forma conjunta, de modo que os três membros do grupo colaboraram acrescentando elementos e situações, criando a história concomitantemente à sua narrativa para o restante dos colegas. É a história do jovem Jailan, que todos os dias fazia o percurso de casa para a escola, mas que certo dia não foi à escola, pois estava doente. Naquele mesmo dia, a escola pegou fogo e caiu uma chuva de sangue "envenenado com Aids", que fez com que todos os que estavam na rua morressem. Apenas Jailan salvou-se, pois ficou em casa. 0 menino era vidente, por isso sabia que naquele dia choveria sangue e não foi para a escola. A história prosseguiu com a afirmação de que o jovem "era satanista, gostava do demônio, era diferente das outras pessoas e por isso todos tinham medo e não gostavam dele". Quando questionei 
sobre como ele se sentia com isso, Gisele respondeu: "Ele não ligava. Ele queria que todo mundo morresse pra ele ser feliz sozinho". Perguntei se isso seria possível e as criadoras da história responderam, demonstrando incerteza em relação ao questionamento sobre a possibilidade de ser feliz sozinho: "Gisele: Foi o que aconteceu. Mas ele ficou triste depois. Laura: Não, ele ficou feliz, até o sol abriu [mostrando no desenho]. Gisele: Ele ficou feliz, mas depois de um tempo ficou triste, porque ele não tinha ninguém. Laura: Ele ficou feliz. Ele tinha os animais, aí ficou feliz. Gisele: Que animais? Eles morreram. Laura: Os animais não, só as pessoas" (G2, $2^{\circ}$ encontro).

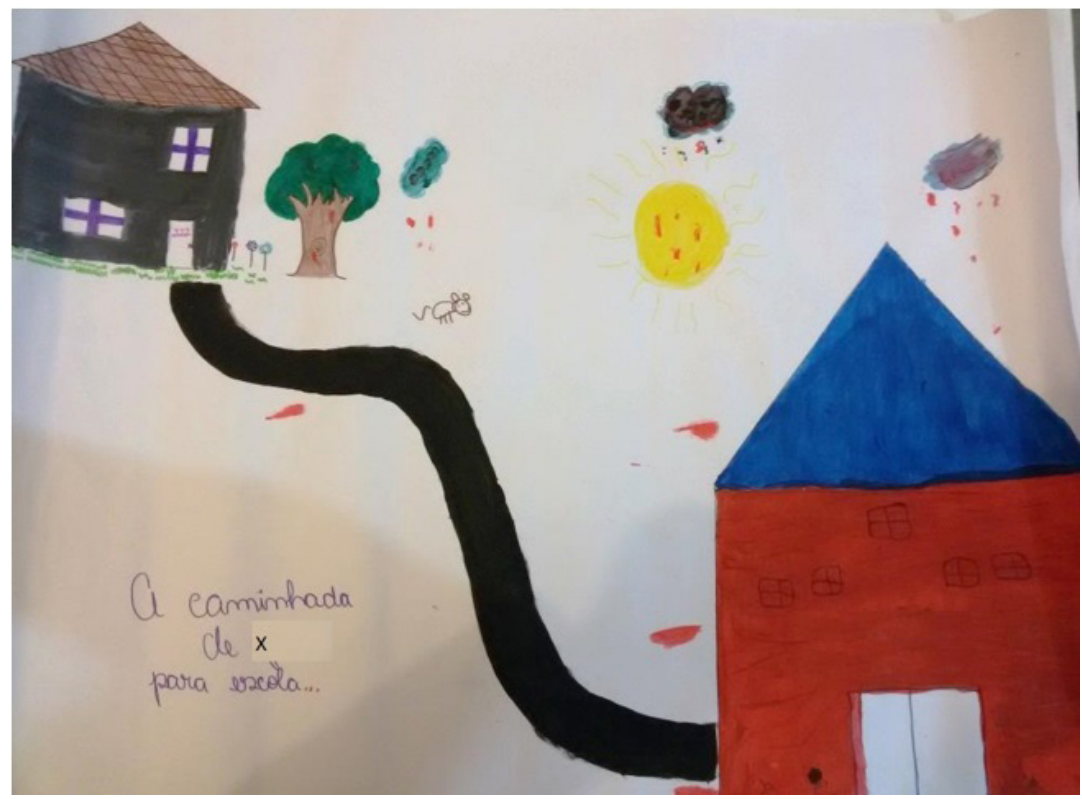

Figura 3. "A chuva de sangue na rua que matou todos os outros" (Jéssica, Laura e Gisele, G2).

Nesta história, tanto a escola quanto a rua aparecem como lugares inoportunos: a escola pega fogo e na rua cai uma chuva de sangue que mata a todos. A casa é retratada como o único lugar seguro, onde a personagem principal permanece e, assim, não se expõe aos riscos presentes nos outros espaços. Na história, a questão da diferença também é retratada, através do personagem Jailan, que incorpora várias diferenças, as quais são negativizadas pelos outros. Isso é motivo de estranhamento e distanciamento dos outros, com quem a convivência se torna difícil. A saída apontada pelos jovens para o problema da convivência com os outros é a realização do desejo de Jailan de que todos morressem para que ele pudesse ser feliz sozinho, ou seja, a aniquilação do outro que causa sofrimento.

É importante problematizar este desejo do sujeito de distanciamento completo e, por vezes, de destruição do outro, uma vez que este é essencial à sua constituição subjetiva. "É precisamente esse Outro que vai confirmar - com o seu olhar, com a sua interação concreta, com as trocas estabelecidas e, principalmente, através do embate com a própria alteridade - uma existência real ao sujeito" (Kuster \& Pechman, 2014b, p. 200).

Quando perguntei ao Grupo 3, no último encontro, o que eles poderiam concluir sobre como é a vida e como são os caminhos que um jovem como eles faz na cidade, Giovana disse: "Eu acho que a vida é boa e o problema são as pessoas". Tal frase é muito significativa e traz novamente a questão do quanto a convivência com o outro 
Pág 66

A rua parece ser experimentada pelos jovens como espaço de encontro quase que exclusivamente em relação àqueles que se conhece e confia. Não parece ser oportunizada como um espaço público/ coletivo, no sentido de que exista a possibilidade de um convívio com a diferença. Isso nos leva a questionar até que ponto estas mobilidades junto aos iguais oportunizam, no sentido de realizarem um deslocamento subjetivo significativo. no espaço público pode ser conflituosa, o que contribui para alimentar o desejo de evitá-la. Podemos, assim, questionar como se constitui a subjetividade desse sujeito que, diante dos embates e conflitos da convivência social, consegue vislumbrar apenas o distanciamento e a destruição da relação com o outro e com a rua como possibilidades de encaminhamento e enfrentamento (Pechman, 2014).

Cabe salientar também que a visão de pacificação, alívio e proteção que a casa oferece não foi vista de forma geral entre os jovens. Em alguns casos, as relações que se estabelecem no espaço doméstico, sobretudo com os adultos, foram referidas pelos jovens como inoportunas, seja pela falta de amparo e acolhimento por parte dos adultos, ou por serem relações que, ao invés de os moverem em direção ao que pode ser oportuno, criam barreiras.

\section{Considerações finais}

Foi possível observar, a partir do campo empírico realizado junto aos jovens, que as mobilidades em relação à rua e a casa evocam afetos diferentes. Enquanto a casa evoca principalmente o imaginário da proteção, acolhimento e abrigo, frequentemente a rua traz à tona o temor e a angústia, pois, ao mesmo tempo em que oferece aventuras, apresenta perigos (Castro, 2004). Em casa, o sujeito não se expõe ao "caos" da rua, mas também não se expõe ao contato com o desconhecido e não-familiar, ao que a rua pode oferecer de desafiador e oportuno. No entanto, nas falas da maioria dos jovens participantes, parece que o perigo e os constrangimentos que a rua representa e a proteção que a casa oferece se sobrepõe ao que a rua pode oferecer em termos de contato com novas experiências e possibilidades.

Ao longo deste artigo, a partir da análise da relação dos jovens com a casa e a rua, foram relatadas situações em que a mobilidade pode (ou não) oportunizar, em que a mobilidade é constrangida (encontra "muros") e situações em que a imobilidade, no sentido da permanência, pode ou não oportunizar. A mobilidade destes jovens na rua é marcada por inoportunidades de toda ordem. A ideia de "caos" associada à experiência urbana foi fortemente destacada pelos jovens. 0 caos barra o movimento e dificulta o acesso ao que pode ser oportuno, pois o sujeito não consegue se organizar subjetivamente e provoca um sentimento de impotência e desamparo. Mover-se pelas ruas dessa cidade caótica é um desafio diário enfrentado por estes jovens, uma vez que são diversos os contrangimentos e embarreiramentos vivenciados por eles.

Cabe salientar que, apesar dos constrangimentos e tensões das vivências na rua, estes jovens não estão totalmente fixados, imóveis e reclusos em casa. Eles ainda ocupam o espaço da rua, mesmo que de forma limitada ao convívio com seus iguais, com os que thes são familiares. Neste sentido, a rua parece ser experimentada pelos jovens como espaço de encontro quase que exclusivamente em relação àqueles que se conhece e confia. Não parece ser oportunizada como um espaço público/coletivo, no sentido de que exista a possibilidade de um convívio com a diferença. Isso nos leva a questionar até que ponto estas mobilidades junto aos iguais oportunizam, no sentido de realizarem um deslocamento subjetivo significativo.

Diante do caos da rua, a retração para o interior do espaço doméstico pode ser uma retração pacificadora, conforme apontado pelos jovens, no sentido de proporcionar uma sensação de maior segurança, por exemplo; no entanto, pode colocar o sujeito numa posição muito mais apática e imobilizada. Assim, podemos questionar ainda que oportunidade é esta que a casa apresenta, uma vez que, apesar da mobilidade 
virtual proporcionada pela Internet, de alguma forma a experiência doméstica muitas vezes não move o sujeito a algum outro lugar, no sentido concreto.

O enclausuramento no espaço doméstico pode impossibilitar um dos aspectos mais fundamentais da cidade: o encontro. 0 espaço urbano possui uma potência que está muito associada aos encontros entre diferenças que nele ocorrem. Esses encontros possibilitam diálogos, embates, articulações, trocas, fundamentais na constituição da vida pública. Quando os sujeitos se enclausuram em suas casas, seja por experiências de constrangimento no espaço público, seja por temor à violência, os diferentes não se encontram e há um enfraquecimento da possibilidade de cidadania (Veloso \& Santiago, 2017).

Por outro lado, podemos considerar que a mobilidade nem sempre está diretamente associada à oportunidade e que a imobilidade nem sempre está relacionada à fixidez e à não oportunização. Assim, quando pensamos na imobilidade no espaço da casa no sentido de uma permanência (em contraponto a uma volatilidade que em alguns casos pode estar associada à mobilidade), esta pode também oportunizar, uma vez que além de possibilitar movimentos imaginários, pode oferecer um sentido de estabilidade e continuidade que oferece sustentação ao processo construção de si.

\section{Referências}

Bardin, L. (2011). Análise de conteúdo. Lisboa: Editora 70. (Original publicado em 1977).

Borelli, S. H. S., \& Rocha, R. M. (2008). Juventudes, midiatizações e nomadismos: a cidade como arena. Comunicação, mídia e consumo, 5(13), 27-40. doi: http://dx.doi. org/10.18568/cmc.v5i13.125

Cassab, C., \& Mendes, J. T. N. (2011). "Perder-se também é caminho": a dimensão espacial da juventude. Libertas On-line, 11(2), 1-18. Disponível em: https://periodicos.ufjf.br/index.php/libertas/article/view/18127/9379

Cassab, M. A. T. (2001). Jovens pobres e a cidade: a construção da subjetividade na desigualdade. In L. R. Castro (Ed.), Crianças e jovens na construção da cultura (pp. 209-226). Rio de Janeiro: NAU Editora; FAPERJ.

Cassab, M. A. T., \& Reis, J. R. (2009). Juventude e cidade: um debate sobre regulação do território. Revista Praia Vermelha, 19(2), 143-154. Disponível em: https://revistas.ufri.br/index.php/praiavermelha/issue/viewlssue/750/260

Cassab, M. A. T., Ribeiro, L. C., \& Schettino, P. (2005). Desigualdade social e território: uma breve reflexão. Anais da II Jornada Internacional de Políticas Públicas. São Luís. Disponível em: http://www.joinpp.ufma.br/jornadas/joinppll/pagina PGPP/Trabalhos2/Maria Aparecida Luiz Claudio Priscila297.pdf

Castro, L. R. (2004). A aventura urbana: crianças e jovens no Rio de Janeiro. Rio de Janeiro: 7Letras.

Castro, L. R. (2013). o futuro da infância e outros escritos. Rio de Janeiro: 7Letras; FAPERJ.

Cecchetto, F. R., Muniz, J. O., \& Monteiro, R. A. (2018). "Basta tá do lado": a construção social do envolvido com o crime. Caderno CRH, 31(82), 99-116. doi: http://dx.doi. org/10.1590/s0103-49792018000100007

Chaves, M., Segura, R., Speroni, M., \& Cingolani, J. (2017). Interdependencias múltiples y asimetrías entre géneros en experiencias de movilidad cotidiana en el corredor sur de la Región Metropolitana de Buenos Aires (Argentina). Revista Transporte y Territorio, 16, 41-67. Disponível em: http://revistascientificas.filo. uba.ar/index.php/rtt/article/view/3602/3297 
Cresswell, T. (2010). Towards a politics of mobility. Environment and Planning D: Society and Space, 28, 17-31. doi: https://doi.org/10.1068/d11407

Dimenstein, M., Zamora, M. H., \& Vilhena, J. (2004). Da vida dos jovens nas favelas cariocas: drogas, violência e confinamento. Revista do Departamento de Psicologia/UFF, 16(1), 23-40. Disponível em: https://www.researchgate.net/profile/ Junia Vilhena/publication/268924221 Da vida dos jovens nas favelas cariocas Drogas violencia e confinamento/links/547b259d0cf293e2da2d34f9/Da-vida-dos-jovens-nas-favelas-cariocas-Drogas-violencia-e-confinamento.pdf

Duarte, A. J. (2014). A periferia como lugar social dos jovens e o processo de escolarização. Revista Iniciação \& Formação Docente, 1(1), 1-18. http://seer.uftm.edu. br/revistaeletronica/index.php/revistagedeles/article/view/944/844

Gough, K. (2008). Moving around: the social and spatial mobility of youth in Lusaka. Geografiska Annaler: Series B, Human Geography, 90(3), 243-255. doi: https://doi. org/10.1111/j.1468-0467.2008.290.x

Gough, K. V., \& Franch, M. (2005). Spaces of the street: socio-spatial mobility and exclusion of youth in Recife. Children's Geographies, 3(2), 149-166. doi: https://doi. org/10.1080/14733280500161560

Kuster, E., \& Pechman, R. (2014a). Apresentação. Intolerância e solidariedade: o chamado da cidade. In E. Kuster \& R. Pechman (Eds.), O chamado da cidade: ensaios sobre a urbanidade (pp. 11-15). Belo Horizonte: Editora UFMG.

Kuster, E., \& Pechman, R. (2014b). Também sem a feli(z) cidade se vive: um panorama dos encontros e desencontros pelas ruas das cidades contemporâneas. In E. Kuster \& R. Pechman (Eds.), O chamado da cidade: ensaios sobre a urbanidade (pp. 187-212). Belo Horizonte: Editora UFMG.

Langevang, T., \& Gough, K. V. (2009). Surviving through movement: the mobility of urban youth in Ghana. Social \& Cultural Geography, 10(7), 741-756. doi: https:// doi.org/10.1080/14649360903205116

Lannes-Fernandes, F. (2012). Os jovens da favela: reflexões sobre controle e contenção sócio-espacial dos párias urbanos no Rio de Janeiro. Convergencia, 19(59), 159186. Disponível em: http://www.scielo.org.mx/scielo.php?script=sci arttext\&pi$\mathrm{d}=\mathrm{S} 1405-14352012000200007$

Medeiros, B. F. (2016). Apresentação. John Urry (1946-2016). Trama: Indústria Criativa em Revista, 1(1). Disponível em: http://revistaadmmade.estacio.br/index.php/ trama/article/view/2273/Apresentacao

Nascimento, C. T. B. (2013). A casa, a rua, a escola: espaços de múltiplas práticas juvenis, Porto Alegre: Editora da UFRGS.

Pechamn, R. (2014). Quando Hannah Arendt vai à cidade e se encontra com Rubem Fonseca. Ou da cidade, da violência e da política. In E. Kuster \& R. Pechman (Eds.), 0 chamado da cidade: ensaios sobre a urbanidade (pp. 17-46). Belo Horizonte: Editora UFMG.

Saraví, G. (2014). Youth experience of urban inequality: space, class, and gender in Mexico. In J. Wyn \& H. Cahill (Eds.), Handbook of childhood and youth (pp. 503-515). Singapura: Springer.

Segura, R. (2017). Ciudad, barreras de acceso y orden urbano: reflexiones sobre juventud, desigualdad y espacio urbano. Revista Argentina de Estudios de Juventud, e16(11), 1-12. doi: https://doi.org/10.24215/18524907e016

Senkevics, A. S., \& Carvalho, M. P. (2015). Casa, rua, escola: gênero e escolarização em setores populares urbanos. Cadernos de Pesquisa, 45(158), 944-968. doi: https://doi.org/10.1590/198053143364

Sheller, M. (2018). Theorising mobility justice. Tempo Social, 30(2), 17-34. doi: https://doi. org/10.11606/0103-2070.ts.2018.142763 
Skelton, T. (2013). Young people's urban im/mobilities: relationality and identity formation.UrbanStudies, 50(3),467-483.doi:https://doi.org/10.1177/0042098012468893

Tapia, S. A. (2018). "No me agrada viajar". Moverse en la ciudad como desafío cotidiano para jóvenes de barrios populares de Buenos Aires. Última Década, 48, 201-233. doi: https://doi.org/10.4067/S0718-22362018000100201

Veloso, S., \& Santiago, V. (2017). Ninguém entra, ninguém sai: mobilidade urbana e direito à cidade no Complexo do Alemão. Rio de Janeiro: Fundação Heinrich Böll. Disponível em: https://br.boell.org/sites/default/files/web livro ninguem entra ninguem sai.pdf

Winton, A. (2005). Youth, gangs and violence: analysing the social and spatial mobility of young people in Guatemala City. Children's Geographies, 3(2), 167-184. doi: https:// doi.org/10.1080/14733280500161537 